\title{
Fat necrosis as a differential diagnosis for recurrence in a treated case of breast cancer: A case report
}

\author{
Avinassh Tippani', Bachu Brahmani² \\ From ${ }^{1}$ Surgical Oncologist - Gastro Surgeon, ${ }^{2}$ Duty Doctor, Department of Surgical Oncology, Sai Shree Hospitals Cancer and Surgical Gastro Centre, \\ Warangal, Telangana, India
}

\begin{abstract}
Fat necrosis is a benign inflammatory process that can involve adipose tissue that most frequently affects peri-menopausal women. It can mimic breast cancer clinically or radiologically. The incidence of breast fat necrosis overall is roughly $0.6 \%$, representing $2.75 \%$ of all benign lesions. Fat necrosis presents in $0.8 \%$ of breast tumors and $1-9 \%$ of breast reduction surgery cases. Most at risk are middleaged women, with an average age of 50 years, and women with pendulous breasts. Traumatic Fat Necrosis is an important differential diagnosis to be kept in mind in Carcinoma Breast patients who are treated with surgery and adjuvant radiation therapy. We present a case where radiation is followed by a large non-healing ulcer in a known case of breast carcinoma patient.
\end{abstract}

Key words: Fat necrosis, Breast carcinoma, Post-radiation ulcer

$\mathrm{B}$ reasts are made up of fatty tissue which if damaged by injury, surgery, or radiation therapy lead to the formation of a lump known as fat necrosis. It is a non-suppurative, inflammatory sterile process that has roots in fat aseptic saponification and changes of adipose tissue. It is a common finding in the post-surgical or post-traumatic breast [1-3]. The etiologic findings of post-treatment fat necrosis are most likely multifactorial with both surgery and radiotherapy having integral roles. Radiation-induced damage to small vessels could lead to lumenal occlusion with ensuing ischemic injury in neighboring tissues. Mild subclinical trauma might then serve as the precipitating event resulting in subsequent fat necrosis. The superficial location of these lesions supports this hypothesis. It is also possible that radiation-induced damage to the ductular epithelium could result in ulceration and eventual perforation with seepage of secretions into surrounding tissue initiating inflammation and subsequent fat necrosis secondary to the release of tissue lipases $[4,5]$. The overall incidence of breast fat necrosis is roughly $0.6 \%$, representing $2.75 \%$ of all benign lesions. Fat necrosis presents in $0.8 \%$ of breast tumors and $1-9 \%$ of breast reduction surgery cases. Most at risk are middle-aged women, with an average age of 50 years, and women with pendulous breasts. This disorder is capable of mimicking breast cancer radiologically and clinically [5-7].

\section{Access this article online}

Received - 16 November 2021

Initial Review - 02 December 2021

Accepted - 10 December 2021

DOI: $10.32677 /$ ijcr.v7i12.3228
We present the case of a 70-year-old female where a large non-healing ulcer is formed on the chest.

\section{CASE REPORT}

A 70-year-old female patient visited our hospital with the complaint of a non-healing ulcer on the chest. She is a known case of carcinoma of the breast 2 years back with a history of post-breast surgery followed by adjuvant radiotherapy and chemotherapy. She was treated with 1.5 Gy with extra beam radiation using cobalt 60 for 25 fractions.

On general examination, her vitals were normal. She has a painful, non-healing ulcer on the chest, Wide local excision of the nodule (Fig. 1a) was made followed by Lattisimus Dorsi flap (LDF) reconstruction (Fig. $1 \mathrm{~b}$ and c). On gross examination, the chest nodule measuring $12 \times 7 \times 1 \mathrm{~cm}$. The external surface was covered by a skin flap. The cut surface shows a lesion measuring $4.3 \times 3 \times 1 \mathrm{~cm}$. The lesion was grey-white and firm inconsistency.

Microscopic examination reveals multiple sections of skin with an underlying nodular lesion showing fat necrosis with aggregates of foamy histiocytes and inflammatory infiltrate comprising predominantly of lymphocytes admixed with few neutrophils. There was no evidence of malignancy in the sections examined. The final impression of the histopathology report suggests that the features are consistent with fat necrosis with no

Correspondence to: Dr. Avinassh Tippani, Surgical Oncologist - Gastro Surgeon, Department of Surgical Oncology, Sai Shree Hospitals Cancer and Surgical Gastro Centre, Warangal, Telangana, India. E-mail: bhuvana.rockers@gmail.com

(C) 2021 Creative Commons Attribution-NonCommercial 4.0 International License (CC BY-NC-ND 4.0). 


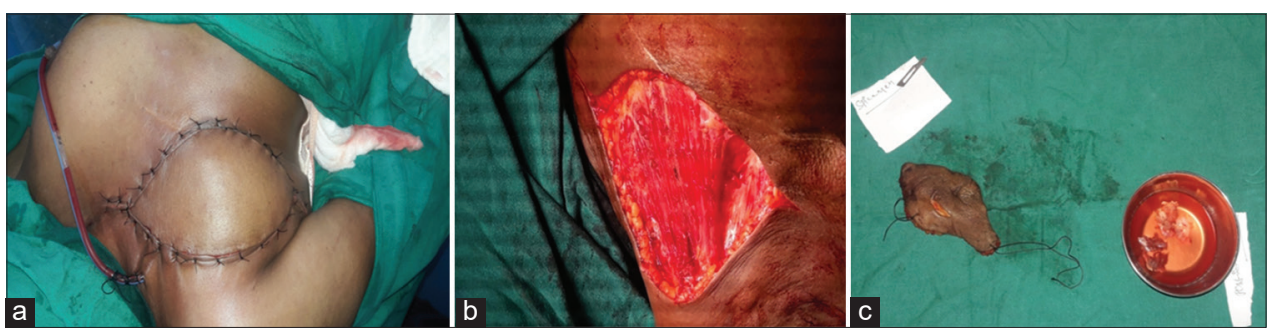

Figure 1: (a) Latissimus dorsi flap reconstruction; (b) wide local excision; (c) removed chest wall nodule post operatively

evidence of residual malignancy in a known case of carcinoma breast surgery. Post-operatively, the patient was doing well.

\section{DISCUSSION}

Fat necrosis is a complex entity from both the clinical and diagnostic aspects. A collection of fused macrophages known as foreign-body giant cells, lipid-laden macrophages, occupying interstices penetration via plasma cells are systematically present. Fat saponification leads to vacuoles formation which then would be surrounded via macrophages.

Fat necrosis is a benign condition that can occur due to iatrogenic breast trauma, some of the main iatrogenic events are breast surgery, lumpectomy, reduction, or augmentation. Some of the other causes include Weber-Christian disease, granulomatous angiopanniculitis, and polyarteritis nodosa. It can occur at any age of a person and appear anywhere on the breast. It develops when the body replaces damaged cells with firm scar tissue. It is difficult to distinguish the clinical and radiographic appearance of breast fat necrosis from that of malignancy. For this purpose, a biopsy is recommended. Some of the main clinical features of fat necrosis are irregular masses with skin retraction and multiple smooth round nodules [4,5].

Therapeutic management via fibrosis would begin at the edge and finally might be replaced with the whole area or evacuate a persevering cystic cavity. In some cases, the cyst content might do not maintain its uniform radiopacity, as a consequence of simulating an abscess, simple cyst, or solid lesion. Distortion of the rim of conglomerate masses would cause the cyst wall edges to become irregular. When the content of the cyst is a combination of both blood and the liquid part of the blood (serum), the mixture could layer on horizontal-beam sidelong films. In such a case, based on highly expressive clinical findings, periodic follow-up of the patients is recommended instead of carrying out a biopsy. In such cases, when there is a nodule in a lipid cyst and incidental calcifications may be present, a biopsy would be recommended. On one hand, it is extremely easy to diagnose fat necrosis in patients with a clear history of breast trauma and the typical findings on imaging. However, the diagnosis could be challenging in patients with suspicious findings on imaging, with or without a prior history of trauma. On the other hand, it can be very difficult to be diagnosed in patients with suspicious imaging findings.

Radiation therapy damage eventually causes non-healing ulcers and soft tissue necrosis. The decreased angiogenesis and persistently high concentration of matrix metalloproteinase indicate a molecular environment in chronic wounds that is hostile to cell replication after injury [8-10]. Radiation-induced ulcers have secondary, progressive, and irreversible characteristics. Once chronic radiation-induced ulcers in the chest wall are formed, they are difficult to heal because of the reduced blood supply, fibrosis, and impaired cellular repair potential associated with radiation therapy $[11,12]$. The most characteristic radiation effects consisted of atypical epithelial cells in the terminal duct lobular unit associated with lobular sclerosis and atrophy. These changes were present in all of the irradiated patients but varied in severity and extent among patients and within individual patients.

\section{CONCLUSION}

Traumatic fat necrosis is an important differential diagnosis to be kept in mind in carcinoma breast patients who are treated with surgery and adjuvant radiation therapy. Among the plethora of breast reconstruction techniques, the LDF is a versatile, reliable means for soft tissue coverage, providing form and function with acceptable preoperative and long-term morbidities for a variety of breast defects. LDF is used most commonly for delayed reconstruction, in patients with previous radiation, or as a salvage procedure in patients with prior failed reconstruction. LDF provides sufficient, vascularized skin and soft tissue. The flap can be molded easily to replace deficient tissue in all areas of the breast.

\section{REFERENCES}

1. Lee BJ, Adair F. Traumatic fat necrosis of the female breast and its differentiation from carcinoma. Ann Surg 1920;72:188-95.

2. Pullyblank AM, Davies JD, Basten J, Rayter Z. Fat necrosis of the female breast--Hadfield re-visited. Breast 2001;10:388-91.

3. Harvey JA, Moran RE, Maurer EJ. Sonographic features of mammary oil cysts. J Ultrasound Med 1997;16:719-24.

4. Bargum K, Nielsen SM. Case report: Fat necrosis of the breast appearing as oil cysts with fat-fluid levels. Br J Radiol 1993;66:718-20.

5. Tan PH, Lai LM, Carrington EV, Opaluwa AS, Ravikumar KH, Chetty N, et al. Fat necrosis of the breast: A review. Breast 2006;15:313-8.

6. Morrow M, Harris JR, Schnitt SJ. Surgical margins in lumpectomy for breast cancer bigger is not better. N Engl J Med 2012;367:79-82.

7. Kerridge WD, Kryvenko ON, Thompson A, Shah BA. Fat necrosis of the breast: A pictorial review of the mammographic, ultrasound, CT, and MRI findings with histopathologic correlation. Radiol Res Pract 2015;2015:613139.

8. Futran ND, Trotti A, Gwede C. Pentoxifylline in the treatment of radiationrelated soft tissue injury: preliminary observations. Laryngoscope 1997; 107:391-5.

9. Dormand EL, Banwell PE, Goodacre TE. Radiotherapy and wound healing. 
Int Wound J. 2005;2:112-7.

10. Goessler UR, Bugert P, Kassner S. In vitro analysis of radiation-induced dermal wounds. Otolaryngol Head Neck Surg 2010;142:845-50.

11. Ferreira PC, Malheiro EL, Pereira JM, Rodrigues JM, Amarante JM. Neglected chest wall radiation-induced ulcers. Breast J 2005;11:215-6.

12. Fujioka M. Surgical reconstruction of radiation injuries. Adv Wound Care (New Rochelle) 2014;3:25-37.
Funding: None; Conflicts of Interest: None Stated.

How to cite this article: Tippani A, Brahmani B. Fat necrosis as a differential diagnosis for recurrence in a treated case of breast cancer: A case report. Indian J Case Reports. 2021;7(12):535-537. 